\title{
Papers
}

\section{Atypical antipsychotic drugs and risk of ischaemic stroke: population based retrospective cohort study}

\author{
Sudeep S Gill, Paula A Rochon, Nathan Herrmann, Philip E Lee, Kathy Sykora, Nadia Gunraj,
} Sharon-Lise T Normand, Jerry H Gurwitz, Connie Marras, Walter P Wodchis, Muhammad Mamdani

\begin{abstract}
Objective To compare the incidence of admissions to hospital for stroke among older adults with dementia receiving atypical or typical antipsychotics.

Design Population based retrospective cohort study.

Setting Ontario, Canada.

Patients 32710 older adults ( $\geq 65$ years) with dementia (17 845 dispensed an atypical antipsychotic and 14865 dispensed a typical antipsychotic).
\end{abstract}

Main outcome measures Admission to hospital with the most responsible diagnosis (single most important condition responsible for the patient's admission) of ischaemic stroke. Observation of patients until they were either admitted to hospital with ischaemic stroke, stopped taking antipsychotics, died, or the study ended.

Results After adjustment for potential confounders, participants receiving atypical antipsychotics showed no significant increase in risk of ischaemic stroke compared with those receiving typical antipsychotics (adjusted hazard ratio $1.01,95 \%$ confidence interval 0.81 to 1.26 ). This finding was consistent in a series of subgroup analyses, including ones of individual atypical antipsychotic drugs (risperidone, olanzapine, and quetiapine) and selected subpopulations of the main cohorts.

Conclusion Older adults with dementia who take atypical antipsychotics have a similar risk of ischaemic stroke to those taking typical antipsychotics.

\section{Introduction}

A variety of behavioural disturbances such as physical aggression, agitation, hallucinations, and wandering commonly accompany dementia. The term behavioural and psychological symptoms of dementia-BPSD-describes this spectrum of noncognitive manifestations of dementia. ${ }^{1}$ The presence of BPSD can decrease quality of life for patients and caregivers, and increases the likelihood of the patient being placed in an institution. $^{2}$

Treatment of BPSD is challenging. A variety of nonpharmacological and pharmacological approaches have been assessed. ${ }^{3}$ Atypical antipsychotics are often prescribed to manage BPSD. Although such prescriptions represent off-label prescribing, this practise is widely endorsed because atypical antipsychotics are among the best studied treatments for BPSD and there is a perception that they have fewer adverse effects than typical antipsychotics. ${ }^{5}{ }^{6}$ Recently, however, concerns have been raised that atypical antipsychotics may increase the risk of cerebrovascular adverse events, including stroke, among older adults with BPSD.

In October 2002, Health Canada and Janssen-Ortho (a manufacturer of atypical antipsychotics) issued a warning to Canadian clinicians of a possible link between risperidone use and cerebrovascular adverse events. ${ }^{7}$ This concern emerged from a clinical trial evaluating risperidone in the management of $\mathrm{BPSD}{ }^{8}$ and a subsequent meta-analysis of the risperidone trials for this indication also showed more cerebrovascular adverse events among participants receiving risperidone (4\%) than among participants receiving placebo $(2 \%) .{ }^{9}$ The US Food and Drug Administration issued a similar warning in April 2003. ${ }^{10}$ More recently, pooled data from clinical trials evaluating olanzapine for BPSD have shown that it may also be associated with an increased risk of cerebrovascular adverse events. ${ }^{11}{ }^{12}$ These data suggest around a threefold increase in the relative risk of cerebrovascular events among people taking risperidone or olanzapine. Based on these data, the UK Committee on Safety of Medicines issued a warning in March 2004 advising that risperidone and olanzapine should no longer be used to manage BPSD, and that patients already receiving these drugs for BPSD should be switched to other treatments. ${ }^{12}$ These warnings have led to controversy among clinicians. ${ }^{13}{ }^{14}$ To date, the warnings only extend to older adults receiving atypical antipsychotics for BPSD and not to patients receiving these drugs for schizophrenia or other indications. No warnings have been issued on the use of other atypical agents, such as quetiapine or aripiprazole, as few studies have been published on their use to manage BPSD. Recent data from a clinical trial of quetiapine to treat BPSD show no increased risk of cerebrovascular adverse events compared with placebo. ${ }^{15}$

The potential link between atypical antipsychotics and cerebrovascular adverse events in patients with BPSD is important, given the common use of these drugs in this patient population. If atypical antipsychotics are thought unsafe, clinicians may consider using typical antipsychotics to treat BPSD. We compared the incidence of admissions to hospitals for stroke among older adults with dementia who received atypical or typical antipsychotics.

\section{Methods}

From administrative healthcare databases in Ontario, Canada, we identified older adults with a diagnosis of dementia and with no history of antipsychotic drug use. In Ontario, a universally funded health programme covers most doctor services, drugs, and hospital services for patients aged 65 and older. We used 
encrypted unique identifiers that are common between the databases to link anonymous information on personal details and use of health services for patients in our study. The linked databases included computerised pharmacy records of the Ontario Drug Benefit Database, which records prescription drugs dispensed to all Ontario residents aged 65 years or older. Records for admission to hospital for acute care were obtained from the Canadian Institute for Health Information Discharge Abstract Database, which uses nomenclature from the ICD-9 (international classification of diseases, 9th revision) to provide detailed diagnostic records for all hospital admissions. We obtained information on doctors' billing for inpatient and outpatient services from the records of the Ontario Health Insurance Plan, and basic personal information and vital statistics for each patient from the Registered Persons Database.

\section{Cohort}

We identified two cohorts within the population of older adults with dementia (Ontario Health Insurance Plan and ICD-9 codes 290, 331, and 797): those who were new users of any of three atypical antipsychotics (risperidone, olanzapine, and quetiapine) and those who were new users of either high potency typical antipsychotics or low potency typical antipsychotics. Typical antipsychotics included in this analysis were haloperidol, fluphenazine, thiothixene, pimozide, trifluoperazine, flupenthixol, zuclopenthixol, thioproperazine, chlorpromazine, thioridazine, mesoridazine, loxapine, perphenazine, promazine, pericyazine, and chlorprothixane. We excluded patients who were receiving non-oral antipsychotics (for example, injectable or depot preparations), and patients with other psychotic disorders such as schizophrenia that might affect their pattern of drug use. The atypical antipsychotic clozapine was not commonly used in Ontario during the period under study, and we therefore excluded patients who were taking this drug. Other atypical antipsychotics (including aripiprazole and ziprasidone) are not currently licensed for use in Canada. We did not include a cohort of non-antipsychotic users, as preliminary data show several important baseline differences between patients receiving antipsychotics and those not receiving antipsychotics. We did not include cohorts of patients taking other psychotropics for BPSD, such as trazadone or valproate, as these are also used for other indications.

\section{Patient observation}

We enrolled patients into the cohorts between 1 April 1997 and 31 March 2002. To restrict our cohorts to new users of antipsychotics, we looked back one year from the first date the antipsychotic was dispensed to ensure that no such drugs had been previously prescribed. We considered that exposure to the antipsychotic had stopped if no further data on a dispensed drug were recorded in the Ontario Drug Benefit Database within a period of two times the total days supplied for the initial date the drug was dispensed. This implied that patients were no longer taking the antipsychotic.

\section{Ischaemic stroke}

Our primary outcome was admission to hospital with a most responsible diagnosis of ischaemic stroke (ICD-9 codes 431, 434, and 436). Validation studies have established an accuracy rate of $90 \%$ for the diagnosis of stroke based on these codes. ${ }^{16}$ Most responsible diagnosis refers to the single most important condition responsible for admission. It is a term used by trained abstractors who complete data collection for the Canadian Institute for Health Information to distinguish between the main rea- son for admission and comorbid conditions. We were therefore able to distinguish between old strokes and new outcome events.

Although the concerns surrounding atypical antipsychotics involve cerebrovascular adverse events, including both transient ischaemic attacks and stroke, we focused exclusively on the outcome of stroke for several reasons: firstly, the diagnostic accuracy for transient ischaemic attacks is relatively poor in administrative databases; secondly, comparatively few patients with transient ischaemic attacks are admitted to hospital; and, thirdly, the risk of stroke in the period immediately after a transient ischaemic attack is high, suggesting that we might capture subsequent events with the coding for stroke. ${ }^{17-20}$

Patients were observed until they were admitted to hospital with ischaemic stroke, stopped taking their antipsychotic, died, or the study ended (31 March 2002). Patients in the cohort receiving atypical antipsychotics were censored if they switched between atypical antipsychotics, to allow us to assess hazards associated with each of the three atypical drugs under study. Patients in the cohort receiving typical antipsychotics were censored if they switched to atypical antipsychotics. The coding accuracy of drug claims in the Ontario Drug Benefit Database is excellent, with an error rate of only $0.7 \%{ }^{21}$

\section{Statistical analysis}

We first calculated crude incidence rates of stroke for the cohorts, using the number of events per 1000 patient years. To examine the independent effect of use of atypical antipsychotics on developing ischaemic stroke, we conducted survival analysis using Cox proportional hazards models. The covariates in our models included factors that would influence the development or the recognition of incident ischaemic stroke. ${ }^{22}$ These factors include age; sex; low income status; residence in long term care; frequency of medical contact (number of physician claim days per patient per year); medical conditions such as prior stroke, atrial fibrillation, diabetes mellitus, acute myocardial infarction in the past three months, congestive heart failure; and overall burden from comorbid disease. As an overall measure of comorbidity, we used the number of distinct drugs dispensed in the year before entry to the cohort, ${ }^{23}$ a measure that performs as well as the Charlson comorbidity index in risk adjustment. ${ }^{24}$ We also controlled for the concomitant use of drugs that might influence the risk of stroke or recognition (for example, antihypertensives, angiotensin converting enzyme inhibitors, lipid lowering drugs, antidiabetic drugs, and hormone replacement therapies). Finally, given the duration of our study and the potential for changes in patient care over this period, we controlled for year of entry to the study. Analyses were performed with SAS for UNIX, version 8.2.

We then carried out subgroup analyses on selected populations of the cohorts. This was done to examine subgroups that either were similar to patients in the trials (for example, most patients in the trials of atypical antipsychotics for managing BPSD were in long term care ${ }^{25}$ ) or were at high risk of stroke (for example, a history of prior stroke or atrial fibrillation). We also examined the risks from use of individual atypical antipsychotic drugs. Finally, we carried out a subgroup analysis of patients enrolled between 1 April 2000 and 31 March 2002. This analysis was done to address major shifts in the prescribing of atypical antipsychotics and typical antipsychotics between 1997 and 2002.

\section{Results}

We identified 32710 older adults with dementia (17845 dispensed atypical antipsychotics and 14865 dispensed typical antipsychotics). The atypical antipsychotic cohort included 
Table 1 Personal characteristics and details of comorbidity in cohorts of older adults ( $\geq 65$ years) with dementia who received atypical antipsychotics or typical antipsychotics. Values are numbers (percentages) unless stated otherwise

\begin{tabular}{|c|c|c|}
\hline Characteristics & $\begin{array}{c}\text { Atypical } \\
\text { antipsychotics } \\
\text { cohort } \\
(\mathbf{n}=17 \text { 845) }\end{array}$ & $\begin{array}{c}\text { Typical } \\
\text { antipsychotics } \\
\text { cohort } \\
(\mathrm{n}=14 \mathrm{865})\end{array}$ \\
\hline Mean (SD) age (years) & $82.5(7.3)$ & $82.7(7.4)$ \\
\hline Men & $6431(36.0)$ & $5727(38.5)$ \\
\hline Long term care & $8485(47.5)$ & $7682(51.7)$ \\
\hline Low income & $6688(37.5)$ & $5807(39.1)$ \\
\hline Urban residence & $2807(15.7)$ & $2673(18.0)$ \\
\hline Mean (SD) frequency of medical contact (days) ${ }^{\star}$ & $33.3(25.4)$ & $34.3(26.8)$ \\
\hline \multicolumn{3}{|l|}{ Year of entry to cohort: } \\
\hline 1997 & $598(3.4)$ & $5452(36.7)$ \\
\hline 1998 & $1588(8.9)$ & $4570(30.7)$ \\
\hline 1999 & $3696(20.7)$ & $2680(18.0)$ \\
\hline 2000 & $5589(31.3)$ & $1321(8.9)$ \\
\hline 2001 & $6374(35.7)$ & $842(5.7)$ \\
\hline Chronic users $\dagger$ & $13792(77.3)$ & $9929(66.8)$ \\
\hline \multicolumn{3}{|l|}{ Overall comorbidity (Charlson comorbidity index score): } \\
\hline No prior admission to hospital & $3969(22.2)$ & $3068(20.6)$ \\
\hline 0 (prior admission with no comorbidities listed) & $6824(38.2)$ & $5173(34.8)$ \\
\hline 1 & $3439(19.3)$ & $3080(20.7)$ \\
\hline 2 & $1795(10.1)$ & $1615(10.9)$ \\
\hline$\geq 3$ & $1818(10.2)$ & $1929(13.0)$ \\
\hline \multicolumn{3}{|l|}{ Conditions affecting risk of stroke: } \\
\hline Prior stroke & $1330(7.5)$ & $1189(8.0)$ \\
\hline Atrial fibrillation & $1992(11.2)$ & $1672(11.2)$ \\
\hline Hypertension & $10894(61.0)$ & $8620(58.0)$ \\
\hline Diabetes mellitus & $3404(19.1)$ & $2756(18.5)$ \\
\hline Acute myocardial infarction & $396(2.2)$ & $391(2.6)$ \\
\hline Congestive heart failure & $4582(25.7)$ & $4130(27.8)$ \\
\hline Endocarditis & $2(<0.1)$ & $1(<0.1)$ \\
\hline Rheumatic heart disease & $317(1.8)$ & $239(1.6)$ \\
\hline Malignant neoplasm & $4771(26.7)$ & $4196(28.2)$ \\
\hline \multicolumn{3}{|l|}{ Procedures affecting risk of stroke: } \\
\hline Electrical cardioversion for atrial fibrillation in past 3 months & $11(0.1)$ & $9(0.1)$ \\
\hline Coronary angiography or angioplasty in past 3 months & $15(0.1)$ & $16(0.1)$ \\
\hline Carotid endarterectomy in past 3 months & $4(<0.1)$ & $1(<0.1)$ \\
\hline \multicolumn{3}{|l|}{ Drug history and drugs affecting risk of stroke: } \\
\hline Mean (SD) total No of drugs per patient & $8.7(5.3)$ & $8.5(5.5)$ \\
\hline Any psychotropic & $10877(61.0)$ & $8731(58.7)$ \\
\hline Benzodiazepines & $7367(41.3)$ & $6420(43.2)$ \\
\hline Warfarin & $1582(8.9)$ & $1248(8.4)$ \\
\hline \multicolumn{3}{|l|}{ Antiplatelets: } \\
\hline Aspirin & $2799(15.7)$ & 2324 (15.6) \\
\hline Ticlopidine & $304(1.7)$ & $263(1.8)$ \\
\hline Clopidogrel & $130(0.7)$ & $22(0.1)$ \\
\hline Combined dipyridamole and aspirin & $14(0.1)$ & $2(<0.1)$ \\
\hline \multicolumn{3}{|l|}{ Antihypertensives: } \\
\hline Diuretics & $2154(12.1)$ & $1500(10.1)$ \\
\hline$\beta$ blockers & $2172(12.2)$ & $1594(10.7)$ \\
\hline Calcium channel blockers & $3345(18.7)$ & $2545(17.1)$ \\
\hline Combination therapies & $88(0.5)$ & $54(0.4)$ \\
\hline Angiotensin II receptor blockers & $274(1.5)$ & $117(0.8)$ \\
\hline Angiotensin converting enzyme inhibitors & $4697(26.3)$ & $3281(22.1)$ \\
\hline 3-hydroxy-3-methylglutaryl-coenzyme A reductase inhibitors & $1324(7.4)$ & $563(3.8)$ \\
\hline Antidiabetic drugs & $2099(11.8)$ & $1681(11.3)$ \\
\hline \multicolumn{3}{|l|}{ Hormone replacement therapies: } \\
\hline Oestrogen & 796 (4.5) & $483(3.2)$ \\
\hline Tamoxifen & $137(0.8)$ & $112(0.8)$ \\
\hline Raloxifene & $8(<0.1)$ & $1(<0.1)$ \\
\hline
\end{tabular}

${ }^{*}$ No of claim days to Ontario Health Insurance Plan per patient per year in year before entry to cohort.

$\dagger \geq 2$ consecutive prescriptions for antipsychotics.

¥Claim to Ontario drug benefit programme for any cholinesterase inhibitor (donepezil, rivastigmine, or galantamine) in year before index (these drugs were first listed on programme in June 1999).
Table 2 Event rates and hazard ratios for older adults with dementia receiving atypical or typical antipsychotics

\begin{tabular}{lcc} 
Main analysis (full cohorts) & $\begin{array}{c}\text { Atypical antipsychotic } \\
\text { cohort }(\mathbf{n}=\mathbf{1 7} \text { 845) }\end{array}$ & $\begin{array}{c}\text { Typical antipsychotic } \\
\text { cohort }(\mathbf{n = 1 4} \text { 865) }\end{array}$ \\
\hline $\begin{array}{l}\text { No (\%) of new admissions for } \\
\text { ischaemic stroke }\end{array}$ & $284(1.6)$ & $227(1.5)$ \\
\hline $\begin{array}{l}\text { Mean (SD) duration of follow up (days) } \\
\text { Crude event rate (No of events per } 1000 \\
\text { person years) }\end{array}$ & $227.2(264.0)$ & $250.1(335.4)$ \\
\hline Unadjusted hazard ratio $(95 \% \mathrm{Cl})$ & 25.5 & 22.3 \\
\hline Adjusted hazard ratio $(95 \% \mathrm{Cl}) \dagger$ & $1.06(0.89$ to 1.27$)$ & 1.00 \\
\hline
\end{tabular}

${ }^{*}$ (No of events/total No of days per 365 days) $\times 1000$.

†Adjusted for age; sex; low income status; residence in long term care; frequency of medical contact; year of entry to cohort; history of stroke in past five years; history of atrial fibrillation hypertension; diabetes mellitus; acute myocardial infarction in past three months; congestive heart failure; number of distinct drugs; chronic use ( $\geq 2$ consecutive prescriptions) of antipsychotics; and baseline use of warfarin, antiplatelet drugs, antihypertensive drugs, angiotensin converting enzyme inhibitors, lipid lowering drugs, antidiabetic drugs, and angiotensin converting enzyme inh

$13503(75.7 \%)$ patients receiving risperidone, 3459 (19.4\%) receiving olanzapine, and $883(4.9 \%)$ receiving quetiapine. Table 1 lists the personal characteristics and comorbidities of patients in both cohorts. In general, the cohorts had similar personal details (standardised differences for most comparisons were $<10 \%$ ). Baseline characteristics were also similar for the subcohorts taking high potency typical antipsychotics (57.1\%) and low potency typical antipsychotics (42.9\%; data not shown). Between 1997 and 2002 a major shift took place towards increased prescribing of atypical antipsychotics. Traditional risk factors for ischaemic stroke, such as atrial fibrillation, hypertension, diabetes, and prior stroke, were common among older adults with dementia (table 1).

In the unadjusted and multivariate analyses, we found that the risk of ischaemic stroke in older adults with dementia receiving atypical antipsychotics was not significantly different from those receiving typical antipsychotics (unadjusted hazard ratio $1.06,95 \%$ confidence interval 0.89 to 1.27 ; adjusted hazard ratio $1.01,0.81$ to 1.26 ; table 2 ).

The subgroup analyses were all consistent with the main analysis as they showed no significant differences in the development of stroke between the cohorts receiving atypical antipsychotics and those receiving typical antipsychotics (table 3 ). The risk of stroke for patients receiving risperidone (adjusted hazard ratio $1.04,0.82$ to 1.31 ), olanzapine $(0.91,0.62$ to 1.32$)$, and quetiapine $(0.78,0.38$ to 1.57$)$ was not significantly different from that of patients receiving typical antipsychotics. Patients dispensed two or more consecutive prescriptions (chronic users) of atypical antipsychotics were not at increased risk of stroke compared with chronic users of typical antipsychotics. Finally, the risk of stroke in the subgroup of patients enrolled between 1 April 2000 and 31 March 2002 was not significantly different between those receiving atypical antipsychotics and those receiving typical antipsychotics (adjusted hazard ratio $0.98,95 \%$ confidence interval 0.65 to 1.47 ).

\section{Discussion}

In this population based cohort, older adults with behavioural and psychological symptoms of dementia (BPSD) who received atypical antipsychotic drugs seem to have a similar risk of admission to hospital for ischaemic stroke as those receiving typical antipsychotic drugs. These findings are important because of the frequency with which atypical antipsychotics are used to manage BPSD. ${ }^{6}$ Our results may help to inform drug prescribing for this group of patients. 
Table 3 Event rates and hazard ratios for subgroup analyses of older adults with dementia receiving atypical or typical antipsychotics

\begin{tabular}{|c|c|c|}
\hline Characteristics & $\begin{array}{c}\text { Atypical } \\
\text { antipsychotics cohort }\end{array}$ & $\begin{array}{c}\text { Typical } \\
\text { antipsychotic cohort }\end{array}$ \\
\hline History of stroke & $(n=1330)$ & $(n=1189)$ \\
\hline $\begin{array}{l}\text { No (\%) of new admissions for ischaemic } \\
\text { stroke }\end{array}$ & $103(7.7)$ & $75(6.3)$ \\
\hline Mean (SD) duration of follow up (days) & $217.1(251.8)$ & $235.0(336.2)$ \\
\hline $\begin{array}{l}\text { Crude event rate (No of events per } 1000 \\
\text { person years) }\end{array}$ & 130.4 & 98.2 \\
\hline Unadjusted hazard ratio $(95 \% \mathrm{Cl})$ & 1.18 (0.88 to 1.59$)$ & 1.00 \\
\hline Adjusted hazard ratio $(95 \% \mathrm{Cl}) \dagger$ & 0.80 (0.55 to 1.16$)$ & 1.00 \\
\hline Long term care resident at baseline & $(n=8485)$ & $(\mathrm{n}=7682)$ \\
\hline $\begin{array}{l}\text { No }(\%) \text { of new admissions for ischaemic } \\
\text { stroke }\end{array}$ & $124(1.5)$ & $98(1.3)$ \\
\hline Mean (SD) duration of follow up (days) & $225.7(267.2)$ & $253.1(336)$ \\
\hline $\begin{array}{l}\text { Crude event rate (No of events per } 1000 \\
\text { person years) }\end{array}$ & 23.7 & 18.4 \\
\hline Unadjusted hazard ratio $(95 \% \mathrm{Cl})$ & $1.18(0.91$ to 1.54$)$ & 1.00 \\
\hline Adjusted hazard ratio $(95 \% \mathrm{Cl}) \dagger$ & $1.15(0.82$ to 1.60$)$ & 1.00 \\
\hline Chronic usersł & $(n=13792)$ & $(\mathrm{n}=9929)$ \\
\hline $\begin{array}{l}\text { No }(\%) \text { of new admissions for ischaemic } \\
\text { stroke }\end{array}$ & $214(1.6)$ & $163(1.6)$ \\
\hline Mean (SD) duration of follow up (days) & $280.6(277.7)$ & $352.7(367.1)$ \\
\hline $\begin{array}{l}\text { Crude event rate (No of events per } 1000 \\
\text { person years) }\end{array}$ & 20.2 & 17 \\
\hline Unadjusted hazard ratio $(95 \% \mathrm{Cl})$ & $1.11(0.91$ to 1.37$)$ & 1.00 \\
\hline Adjusted hazard ratio $(95 \% \mathrm{Cl}) \dagger$ & 0.89 (0.69 to 1.17$)$ & 1.00 \\
\hline History of atrial fibrillation & $(n=1992)$ & $(n=1672)$ \\
\hline No (\%) of admissions for ischaemic stroke & $52(2.6)$ & $34(2.0)$ \\
\hline Mean (SD) duration of follow up (days) & $195.6(233.1)$ & $195.6(288.6)$ \\
\hline $\begin{array}{l}\text { Crude event rate (No of events per } 1000 \\
\text { person years) }\end{array}$ & 48.8 & 38 \\
\hline Unadjusted hazard ratio $(95 \% \mathrm{Cl})$ & 1.23 (0.79 to 1.89$)$ & 1.00 \\
\hline Adjusted hazard ratio $(95 \% \mathrm{Cl}) \dagger$ & 1.23 (0.70 to 2.02$)$ & 1.00 \\
\hline
\end{tabular}

*(No of events/total No of days per 365 days $) \times 1000$.

†Adjusted for age; sex; low income status; residence in long term care; frequency of medical contact; year of entry to cohort; history of stroke in past five years; history of atrial fibrillation; hypertension; diabetes mellitus; acute myocardial infarction in past 3 months; congestive heart failure; number of distinct drugs; chronic use ( $\geq 2$ consecutive prescriptions) of antipsychotics; baseline use of warfarin, antiplatelet drugs, antihypertensives, angiotensin converting enzyme inhibitors, lipid lowering drugs, antidiabetic drugs, and hormone replacement therapy. Factors not included in risk adjustment when they were focus of subgroups analysis were residence in long term care, history of stroke in past five years, history of atrial fibrillation, and chronic use of antipsychotics.

$\ddagger \geq 2$ consecutive prescriptions.

The findings from our main analysis were consistent with those for all subgroups we tested. The incidence rates for stroke corresponded well with those reported by other investigators and highlight the relatively high risk of ischaemic stroke among older adults with dementia. ${ }^{26}$ We found higher incidence rates of stroke in those subgroups with established risk factors for stroke, such as atrial fibrillation and prior stroke, than in the main analysis. In contrast, we found no increase in risk among chronic users (two or more consecutive prescriptions) of atypical antipsychotics, suggesting the absence of an association between atypical antipsychotics and cerebrovascular events. In effect, with increasing duration of exposure there seems to be no increased risk of the outcome.

Several investigators found no association between use of atypical antipsychotics and cerebrovascular events. ${ }^{27-29}$ In addition, recent data from a trial evaluating quetiapine for BPSD showed no increased risk of cerebrovascular adverse events compared with placebo. ${ }^{15}$ Our large population based study supports these findings. In contrast, earlier clinical trials of risperidone and olanzapine reported a link between use of atypical antipsychotics and cerebrovascular adverse events, including ischaemic stroke. ${ }^{911}$ It could be speculated that in these trials events other than transient ischaemic attacks and strokes were classified as "cerebrovascular adverse events." If atypical agents do contribute to the risk of stroke, however, a plausible biological rationale must exist. The risk seems to develop quickly (6-12 weeks in clinical trials), and thus it seems unlikely that the risk is mediated through drug effects on risk factors such as glucose or lipid metabolism. Similarly, drug induced atrial fibrillation would be an unlikely explanation for such a rapid increase in the risk of cerebrovascular adverse events. Potential mechanisms for cerebrovascular events related to atypical antipsychotics might include orthostatic hypotension in patients with pre-existing cerebrovascular disease, which might lead to "watershed" strokes, ${ }^{14}$ and antipsychotic induced hyperprolactinaemia, which might promote platelet aggregation. ${ }^{140}$ Others, however, have reported that risperidone may inhibit platelet aggregation (through serotonin receptor antagonism), rather than promote it. $^{31}$ Some observational data have shown that antipsychotics might be associated with an increased risk of venous thromboembolic disease ${ }^{32}$; arterial thrombosis such as stroke, however, shares few risk factors with venous thrombosis. In summary, a clear biological rationale has not yet been identified for an increased risk of stroke associated with use of atypical antipsychotics. The collection of data on "cerebrovascular adverse events" may have been influenced by patients' receipt of active drug therapy or placebo in the clinical trials. For example, it is possible that patients given antipsychotic treatment with relief of psychoses might report more symptoms than patients given placebo. $^{14}$

\section{Limitations of study}

Our study has several potential limitations. Firstly, our study was observational, and although the baseline differences between our cohorts were minor, we may not have been able to adjust adequately for such differences. Important confounders may also have been unmeasured and unrecognised. We tried to avoid confounding by indication by specifically excluding data from the period after the first warning of cerebrovascular adverse events was issued (October 2002). ${ }^{7}$ Before this time, the choice between typical antipsychotics and atypical antipsychotics was not affected by concerns about such adverse events. A second limitation is the possibility of ascertainment bias because some strokes may not have been captured if they did not lead to admission to hospital or if they led immediately to death. Despite the potential for ascertainment bias, we kept our primary outcome as admission to hospital for stroke given the accuracy with which this diagnosis is captured in the data we used. We believe that most strokes in this patient population would have resulted in hospital admission. Thirdly, given the limitations of the administrative data, we could not adjust for all of the important factors affecting the risk of stroke, such as smoking history, presence and severity of hypertension, lipid status, and specific valvular heart conditions.

What do these results mean for clinical practice? Clinicians managing patients with dementia who develop behavioural disturbances should initially rule out underlying medical illnesses or drugs that might predispose to delirium. ${ }^{33}$ If BPSD is diagnosed, clinicians should initially consider nonpharmacological harm reduction strategies such as education of family members, $\mathrm{ABC}$ charting, and music therapy. ${ }^{3}$ If pharmacotherapy is considered necessary, it should be tailored to the individual. Our data show that the risk of ischaemic stroke is similar for patients receiving atypical antipsychotics and those receiving typical antipsychotics. Other potential risks of antipsychotics (for example, extrapyramidal symptoms, tardive dyskinesia) should also be weighed against the benefits. A 


\section{What is already known on this topic}

Atypical antipsychotics are commonly used to manage behavioural and psychological symptoms of dementia (BPSD)

Recent evidence from clinical trials suggests an association between atypical antipsychotic use and cerebrovascular events (including stroke) among older adults with BPSD

These data prompted the UK Committee on Safety of Medicines to recommend against the prescribing of atypical antipsychotics to patients with BPSD

\section{What this study adds}

Use of atypical antipsychotics by patients with dementia is not associated with a greater risk of stroke is than use of typical antipsychotics

Findings were consistent for a series of subgroup analyses including ones for patients at high baseline risk of stroke

The choice of atypical or typical antipsychotics to manage BPSD should not be based on concerns about the risk of stroke

working group of psychiatrists, general practitioners, and geriatricians in the United Kingdom has developed guidelines for the management of BPSD in people with a history of stroke or transient ischaemic attack. ${ }^{34}$ Unfortunately, many of the alternatives to atypical antipsychotics for managing BPSD have received only limited evaluation and have their own important adverse event profiles. ${ }^{4}$ The US National Institute of Mental Health is currently sponsoring the clinical antipsychotic trials of intervention effectiveness (CATIE) Alzheimer's disease trial, which is a 36 week study comparing three atypical antipsychotics, a selective serotonin reuptake inhibitor, and placebo to treat BPSD. Results are due in 2006. ${ }^{35}$ This study and others ${ }^{36}$ should shed light on the optimal management of BPSD and the risk of stroke in this patient population.

We thank the following members of the New Emerging Team for their input: S Garfinkel, C Bell, GM Anderson, MP Hillmer, and A Bierman.

Contributors: SSG, PAR, NH, PEL, and MM conceived the study. All authors contributed to the study design. KS, NG, and SSG performed the data analysis. SSG wrote the initial draft, and all authors critically revised the manuscript. PAR and MM were overseers of the research network. SSG will act as guarantor for the paper.

Funding: SSG was supported by a Canadian Institutes of Health Research postdoctoral fellowship and the Annie Kirshenblatt Memorial scholarship. PAR is supported by a Canadian Institutes of Health Research Investigator Award. Eli Lilly Canada partly supported PEL's behavioural neurology fellowship. This work was supported by a Canadian Institutes of Health Research Chronic Disease New Emerging Team programme grant (NET 54010). The NET programme receives joint sponsorship from the Canadian Diabetes Association, the Kidney Foundation of Canada, the Heart and Stroke Foundation of Canada, and the Canadian Institutes of Health Research Institutes of Nutrition, Metabolism, and Diabetes, and Circulatory and Respiratory Health. MM was supported in part by a New Investigator Award through the NET programme.

Competing interests: NH has received research support and speaker's honoraria from Janssen-Ortho, Eli Lilly, Novartis, Pfizer, and Astra Zeneca, manufacturers of atypical antipsychotics.

Ethical approval: This study was approved by the ethics review board of Sunnybrook and Women's College Health Sciences Centre.

1 Cohen-Mansfield J, Billig N. Agitated behaviours in the elderly. I: a conceptual review. J Am Geriatr Soc 1998;36:7-12.
2 Cohen CA, Gold DP, Shulman KI, Wortley JT, McDonald G, Wargon M. Factors determining the decision to institutionalize dementing individuals: a prospective study. Gerontologist 1993;33:714-20.

3 Teri L, Logsdon RG, McCurry SM. Nonpharmacologic treatment of behavioral disturbance in dementia. Med Clin North Am 2002;86:641-56.

4 Tariot PN, Ryan JM, Porsteinsson AP, Loy R, Schneider LS. Pharmacologic therapy for behavioral symptoms of Alzheimer's disease. Clin Geriatr Med 2001;17:359-76.

5 Doody RS, Stevens JC, Beck C, Dubinsky RM, Kaye JA, Gwyther L, et al. Practice parameter: management of dementia (an evidence-based review). Report of the Quality Standards Subcommittee of the American Academy of Neurology. Neurology 2001;56:1154-66.

6 Liperoti R, Mor V, Lapane KL, Pedone C, Gambassi G, Bernabei R. The use of atypical antipsychotics in nursing homes.J Clin Psychiatry 2003;64:1106-12.

7 Health Canada, important drug safety information: RISPERDAL* (risperidone) and cerebrovascular adverse events in placebo-controlled dementia trials-Janssen-Ortho. www.hc-sc.gc.ca/hpfb-dgpsa/tpd-dpt/risperdal1_e.html (accessed 15 Nov 2004).

8 Brodaty H, Ames D, Snowden J, Woodward M, Kirwan J, Clarnette R, et al. A randomized placebo controlled trial of risperidone for the treatment of aggression, agitation, and psychosis in dementia. J Clin Psychiatry 2003;64:134-43.

9 Wooltorton E. Risperidone (Risperdal): increased rate of cerebrovascular events in dementia trials. CMAJ 2002;167:1269-70.

102003 Safety alert: RISPERDAL (risperidone). Washington, DC: US Food and Drug Administration; 1 Mar 2004. www.fda.gov/medwatch/SAFETY/2003/risperdal.htm (accessed 15 Nov 2004).

11 Wooltorton E. Olanzapine (Zyprexa): increased incidence of cerebrovascular events in dementia trials. CMAJ 2004;170:1395.

12 Atypical antipsychotic drugs and stroke: message from Professor Gordon Duff, Chairman, Committee on Safety of Medicines (CEM/CMO/2004/1). www.mca.gov.uk/ ourwork/monitorsafequalmed/safetymessages/antipsystroke_9304.htm (accessed 15 Nov 2004).

13 Mowat D, Fowlie D, MacEwan T. CSM warning on atypical psychotics and stroke may be detrimental for dementia. BMJ 2004;328:1262-b.

14 Smith DA, Beier MT. Association between risperidone treatment and cerebrovascular adverse events: examining the evidence and postulating hypotheses for an underlying mechanism. J Am Med Dir Assoc 2004;5:129-32.

15 Quetiapine evaluated for agitation in people with Alzheimer's. www.alz.org/ internationalconference/Pressreleases/072204_hottopics.doc (accessed 15 Nov 2004). 16 Mayo NE, Chockalingam A, Reeder BA, Phillips S. Surveillance for stroke in Canada. Health Rep 1994;6:62-72.

17 Gladstone DJ, Kapral MK, Fang J, Laupacis A, Tu JV. Management and outcomes of transient ischemic attacks in Ontario. CMAJ 2004;170:1099-104

18 Johnston SC, Gress DR, Browner WS, Sidney S. Short-term prognosis after emergency department diagnosis of TIA. JAMA 2000;284:2901-6.

19 Coull AJ, Lovett JK, Rothwell PM. Population based study of early risk of stroke after transient ischaemic attack or minor stroke: implications for public education and organisation of services. BMJ 2004;328:326-8.

20 Hill MD, Yiannakoulias N, Jeerakathil T, Tu JV, Svenson LW, Schopflocher DP. The high risk of stroke immediately after transient ischemic attack: a population-based study. Neurology 2004;62:2015-20.

21 Levy AR, O'Brien BJ, Sellors C, Grootendorst P, Willison D. Coding accuracy of administrative drug claims in the Ontario drug benefit database. Can J Clin Pharmacol 2003;10:67-71.

22 Straus SE, Majumdar SR, McAlister FA. New evidence for stroke prevention: scientific review. JAMA 2002;288:1388-95.

23 Schneeweiss S, Seeger JD, Maclure M, Wang PS, Avorn J, Glynn RJ. Performance of comorbidity scores to control for confounding in epidemiologic studies using claims data. Am J Epidemiol 2001;154:854-64.

24 Charlson ME, Pompei P, Ales KL, MacKenzie CR. A new method of classifying prognostic comorbidity in longitudinal studies: development and validation.J Chronic Dis 1987:40:373-83.

25 Lee PE, Gill SS, Freedman M, Bronskill SE, Hillmer MP, Rochon PA. Atypical antipsychotic therapy in the treatment of behavioural and psychological symptoms of dementia: systematic review. BMJ 2004;329:75-8.

26 Hollander M, Koudstaal PJ, Bots ML, Grobbee DE, Hofman A, Breteler MM. Incidence, risk, and case fatality of first ever stroke in the elderly population: the Rotterdam study. J Neurol Neurosurg Psychiatry 2003;74:317-21.

27 Herrmann N, Mamdani M, Lanctôt KL. Atypical antipsychotics and risk of cerebrovascular accidents. Am J Psychiatry 2004;161:1113-5.

28 Liperoti R. Cerebrovascular events among elderly patients treated with conventional or atypical antipsychotics. 2004 Annual meeting of the American Geriatrics Society. atypical antipsychotics. 2004 Annual meeting of the American Geriatrics Society.
www.americangeriatrics.org/news/meeting/schedule events.pdf (accessed 15 Nov www.an).

29 Kozma CM, Engelhart LM, Long S, Greenspan A, Mahmoud R, Baser O. Absence of increased relative stroke risk in elderly dementia patients treated with risperidone versus other antipsychotics. 2003 meeting of the International College of Geriatric Psychoneuropharmacology. www.icgp.org/ICGP_2003_program_Book.pdf (accessed 15 Nov 2004).

30 Wallaschofski H, Donne M, Eigenthaler M, Hentschel B, Faber R, Stepan H, et al. PRL as a novel potent cofactor for platelet aggregation. J Clin Endocrinol Metab 2001;86:5912-9.

31 Harrison-Woolrych M, Clark DWJ. Nose bleeds associated with use of risperidone. BMJ 2004;328:1416

32 Zornberg GL, Jick H. Antipsychotic drug use and risk of first-time idiopathic venous thromboembolism: a case-control study. Lancet 2000;356:1219-23.

33 Brown TM, Boyle MF. Delirium. BMJ 2002;325:644-7.

34 Guidance for the management of behavioural and psychiatric symptoms in dementia and the treatment of psychosis in people with history of stroke/TIA. Working group for the Faculty of Old Age Psychiatry RCPsych, RCGP, BGS, and Alzheimer's Society, for the Faculty of Old Age Psychiatry RCPsych, RCGP, BGS, and Alzheimer's Society,
following CSM restriction on risperidone and olanzapine. www.bgs.org.uk following CSM restriction on risperidone and olanzapine. www.bgs.org.uk/
publications/CSM $\% 20$ anouncement $\% 2009 \% 2003 \% 202004$.pdf (accessed 15 Nov 2004). 
35 Schneider LS, Tariot PN, Lyketsos CG, Dagerman KS, Davis KL, Davis S. National nstitute of Mental Health clinical antipsychotic trials of intervention effectivenes (CATIE): Alzheimer's disease trial methodology. Am J Geriatr Psychiatry 2001;9:346-60. 36 The CALM-AD trial-a randomised clinical trial of a cholinesterase inhibitor and atypical antipsychotic in the management of agitation in dementia. www.ihs.ox.ac.uk csm/rep\%20RCT.html\#_Toc21853935 (accessed 15 Nov 2004).

(Accepted 1 December 2004)

doi $10.1136 /$ bmj.38330.470486.8F

Institute for Clinical Evaluative Sciences, 2075 Bayview Avenue, Toronto, ON, Canada

Sudeep S Gill adjunct scientist

Kathy Sykora senior biostatistician

Nadia Gunraj biostatistician

Muhammad Mamdani scientist

Kunin-Lunenfeld Applied Research Unit, Baycrest Centre for Geriatric Care, Toronto

Paula A Rochon assistant director

Division of Geriatric Psychiatry, Department of Psychiatry, Sunnybrook and
Women's College Health Sciences Centre, Toronto

Nathan Herrmann head

Morton and Gloria Shulman Movement Disorders Centre, Toronto Western Hospital, Toronto

Connie Marras neurologist

Toronto Rehabilitation Institute, Toronto

Walter P Wodchis scientist

Division of Geriatric Medicine, University of British Columbia, Vancouver, BC, Canada

Philip E Lee geriatrician

Department of Health Care Policy, Harvard Medical School and Harvard School of Public Health, Boston, MA, USA

Sharon-Lise T Normand professor of biostatistics

Meyers Primary Care Institute, University of Massachusetts Medical School, Worcester, MA

Jerry H Gurwitz professor

Correspondence to: S S Gill, Room 1-152, Chapel Wing, St Mary's of the Lake Hospital, 340 Union Street, Kingston, ON, Canada K7L 5A2 gills@pccchealth.org 